\title{
RELASI INTELEKTUALITAS DAN SPIRITUALITAS DALAM BERAPOLOGETIKA: SUATU TINJAUAN INJILI
}

\author{
Nathanail Sitepu \\ Sekolah Tinggi Teologi Internasional Harvest Semarang \\ Email: psnail21@gmail.com
}

\begin{abstract}
ABSTRAK
Artikel ini menyoroti pendapat yang menyatakan bahwa kegiatan berapologetika adalah kegiatan yang hanya mengasah intelektual tetapi tidak berdampak terhadap spiritualitas atau kerohanian seseorang. Akibatnya argumentasi yang disampaikan bahwa kegiatan apologetika yang saat ini marak di media sosial hanya berujung pada debat kusir atau saling serang dan saling merendahkan satu sama lain. Seringkali yang menonjol adalah egoisme sektarian bukan kasih untuk memenangkan jiwa kepada Kristus. Metode yang digunakan adalah pendekatan literature research, kemudian menganalisis dengan pendekatan analitis komparatif dalam mengkaji kegiatan berapologetika yang berkaitan dengan intelektualitas dan spiritualitas. Kajian artikel ini mengungkapkan bahwa Apologetika memiliki kaitannya yang erat dengan pengembangan intelektualitas dan spiritualitas seseorang. Adanya kegagalan oleh sebagian apologet untuk menunjukkan kedewasaan spiritualitasnya dalam perdebatan, tidak lantas menjadi ukuran final bahwa apologetika tidak membawa orang semakin dekat dengan Tuhan. Kesimpulan yang ditemukan adalah adanya korelasi yang kuat bagi perkembangan intelektualitas dan spiritualitas ketika seseorang berapologetika. Hal ini disebabkan karena apologetika mendorong seseorang mendalami Kitab Suci dan belajar untuk memahami, membahasakan, dan melakukannya.
\end{abstract}

Kata-kata kunci: Apologetika, Intelektualitas, Spiritualitas, Injil, Iman

\begin{abstract}
This article highlights the opinion which states that apologetic activities are activities that only hone intellectually but have no impact on one's spirituality or spirituality. As a result, the argument is that apologetic activities currently rife on social media only end in debating with coaches or attacking and humiliating one another. Often what stands out is sectarian egoism, not love for winning souls to Christ. The method used is a literature research approach, then analyzed with a comparative analytical approach in assessing apologetic activities related to intellectuality and spirituality. The study of this article reveals that Apologetics is closely related to the development of one's intellect and spirituality. The failure by some apologists to show the maturity of their spirituality in debate, does not necessarily become the final measure that apologetics does not bring people closer to God. The conclusion that is found is that there is a strong correlation for the development of intellectuality and spirituality when someone is apologetic. This is because apologetics encourages a person to study the Scriptures and learn to understand, pronounce, and do it.
\end{abstract}


Keywords: Apologetics, Intellectuality, Spirituality, Gospel, Faith

\section{PENDAHULUAN}

Kegiatan berapologetika merupakan hal yang penting dalam kehidupan Kristen. Pada dasarnya Apologetika adalah suatu aktifitas yang dilakukan untuk membela atau mempertahankan iman Kristen terhadap serangan-serangan dari luar. Di dalam Alkitab, bahkan dalam sejarah Kekristenan sendiri, Alkitab dan dogma Kristen sering menjadi olok-olokkan oleh agama lain maupun juga kaum ateis.(Tri Handoko, 2018) Apologetika sendiri merupakan kegiatan yang sangat alkitabiah. Di dalam berapologetika harusnya melibatkan iman dan rasio sekaligus. Sebab apologetika merupakan aktifitas untuk mempertanyakan apa yang diimani dan menjawab apa yang menjadi pertanyaan atau serangan terhadap iman Kristen. Namun, banyak orang yang memandang negatif tentang kegiatan berapologetika. Dalam akun Youtube Grace Alone Ministry, penulis menemukan beberapa komentar yang menyatakan bahwa dalam pengalamannya menyaksikan perdebatan teologis sering berujung dengan penghinaan, perendahan, dan penghujatan terhadap lawan debat. Kegiatan apologetika menurutnya seringkali menjadi ajang menunjukkan kehebatan denominasi atau mazhab teologi tertentu, dan dengan agama lain juga seringkali malah semakin menciptakan jurang persahabatan.

Di tengah pandangan negatif tentang apologetika yang seringkali dipandang sebagai perang argumen semata, Stackhouse menyatakan bahwa sesungguhnya apologetika tidak boleh hanya menyentuh intelektualitas seseorang saja, melainkan apologetika harus menjadi sarana untuk menyentuh seluruh kehidupan seseorang agar terjadi transformasi (conversion) dalam kehidupan tersebut(Stackhouse, Jr., 2002).

\section{METODE}

Dalam artikel ini penulis melakukan penelitian dengan metode fenomenologi, dimana penulis melihat fenomena yang terjadi akhir-akhir ini dalam dunia apologetika secara khusus di Indonesia, dan mengamati permasalahan yang terjadi dimana kegiatan berapologetika memiliki konotasi negatif, dan menganalisa pemikiran Dahle Karls yang menyatakan bahwa kegiatan Apologetika adalah suatu kegiatan menyampaikan iman Kristen secara sistematis, konsisten, dan kemudian terbukti nyata dalam kehidupan 
seorang Apologis Kristen (Dahle, 2013). Penulis kemudian menganalisis dengan menggunakan literatur research, dan mengambil suatu kesimpulan. Fenomenologi adalah salah satu dari beberapa jenis metode penelitian kualitatatif. Kegunaannya ialah untuk mengungkap adanya kesamaan makna atau esensi dari suatu kejadian ataupun fenomena yang dialami oleh seseorang atau kelompok tertentu dalam aktifitas kehidupannya. Fenomenologi ini sendiri dicetuskan oleh Edmun Husserl (1859-1938), yang berfungsi sebagai metode yang dapat mengungkapkan esensi dengan pendekatan hermeneutika (Hasbiansyah, 2005:164).

\section{HASIL DAN PEMBAHASAN}

\section{Apologetika dan Intelektualitas}

Apologetika Kristen adalah upaya yang dilakukan seorang Apologis Kristen untuk membela atau mempertahankan imannya terhadap pihak-pihak yang meragukan atau bahkan menentang ajaran-ajaran iman Kristen. Kegiatan berapologetika disampaikan secara sistematis, dan rasional. Orang yang ahli dalam bidang ini disebut Apologis Kristen. Kata Apologetika sendiri berasal dari kata dalam bahaya Yunani, yaitu Apologia, yang menunjuk kepada kegiatan mempertahankan dan memberikan jawaban asal (Brown, 1975). Salah satu contoh penggunaan kata Apologia yang paling terkenal dalam literatur Yunani adalah pembelaan yang dilakukan oleh Sokrates saat diadili di Athena (Tri Handoko, 2020).

Alkitab mencantumkan kata Apologia sebanyak delapan kali (Kisah Para Rasul 22:1; 25:16; 1 Korintus 9:3; 2 Korintus 7:11; Filipi 1:7, 16; 2 Timotius 4:16; 1 Petrus 3:15). Dan untuk kata kerja Apologeomai (membela) tercantum sebanyak 10 kali (Lukas 12:11; 21:14; Kisah Para Rasul 19:33; 24:10; 25:8; 26:1, 2, 24; Roma 2:15; 2 Korintus 12:19). Berdasarkan ayat-ayat tersebut, maka secara umum kata Apologia dan Apologeomaia menunjuk kepada suatu pembelaan baik secara hukum, pribadi, juga doktrinal. Dalam konteks Kristen, kegiatab berapologetika dipergunakan untuk membela iman Kristen kepada pihak-pihak yang salah memahami inti doktrin dalam kekristenan, baik oleh pihak orang Kristen sendiri, maupun juga dari pihak non-Kristen yang bahkan bertujuan untuk memberantas iman Kristen (Djadi, 2003). Aktifitas ini telah dimulai oleh para Rasul, dan Bapa gereja yang pada masa itu gencar diserang oleh para pengajar sesat juga oleh kekuasaan politik, yaitu pemerintah Romawi yang sangat 
resah akan pertumbuhan iman Kristen. Dalam perkembangan selanjutnya, dimana dunia filsafat berkembang ke arah paradigma Aristotelianisme, maka para pejuang Apologetika Kristen mulai membangun pola yang berbeda. Teologi dan Filsafat menjadi dua kubu yang bersaing dalam merebut hati dan pikiran orang-orang pada zaman itu. Iman dan rasio ibarat benih yang bertumbuh dan berkembang. Tokoh-tokoh pembela iman yang terkenal pada masa Skolastik antara lain: Thomas Aquinas, Anselmus, William Ochan, dan Dons. Dalam perjalanan sejarah gereja, telah muncul kisah-kisah heroik dari para Giant of faith yang dengan penuh keberanian mempertahankan dan mempertanggungjawabkan iman di dalam momennya masingmasing. Tuhan memakai tindakan Apologetik Martin Luther, seorang biarawan sekaligus dosen teologi dari sebuah universitas kecil di kota Wittenberg, Jerman, untuk melakukan Reformasi yang pada akhirnya mengubah jalannya sejarah Eropa. Luther menolak doktrin dan pratek penjualan Surat Penghapusan dosa, yang ditukar dengan nominal uang (Taufik, 2020). Luther dengan segala resiko yang berat dengan lantang menentang doktrin tersebut. Luther menekankan prinsip Sola Scriptura. Menurut Luther, keadilan Tuhan dan teguran-Nya merupakan wujud dari objektivitas Tuhan sendiri, sementara pengampunan adalah wujud kasih-Nya kepada manusia. Pemikiran Luther bahkan digunakan sebagai kritikan terhadap kondisi gereja masa itu, dan menjadi sebuah dasar pembentukan model etika non-objektivitas dalam kode etik profesi Akuntan (Pratiwi, 2020).

Apologetika dapat dilihat sebagai cara yang dipakai oleh Tuhan dari zaman ke zaman untuk memurnikan dan memperluas jangkauan iman Kristen. John Calvin menyusun sebuah buku Institutio edisi pertama untuk membela orang-orang Kristen dari penganiayaan oleh kekuasaan politis Perancis kala itu. Dalam Institutio, Calvin memaparkan konsep dunia adalah teater kemuliaan Allah, dimana manusia yang ada di dalam dunia ini dapat merasakan "pengalaman religius" bersama dengan Allah melaui pengetahuan dan pengalaman hidup (Yosia, 2018). Selanjutnya secara singkat seorang apologis Kristen selalu hadir dan sangat diperlukan di dalam membendung kritikan dan hinaan terhadap iman Kristen, seperti C.S. Lewis, Van Till, dll. Apologetika membutuhkan kemampuan berpikir dan berbicara secara logis-teologis untuk memproklamirkan kebenaran iman Kristen. Sehingga segala pemikiran yang menentang kebenaran Allah, dapat diruntuhkan dan memberikan kebangunan 
imanTentu tidak dapat diabaikan perlunya penguasaan sains atau ilmu pengetahuan yang cukup bagi para apologis agar selain tetap kritis, tetapi juga tidak cepat memberi pandangan yang bertolak belakang jauh dengan pengetahuan umum (parapat, 2020). Sehingga segala pemikiran yang menentang kebenaran Allah, dapat diruntuhkan dan memberikan kebangunan iman (Tulung, 2020), seperti pernyataan Rasul Paulus: Aku tahu kepada siapa aku percaya (2 Tim. 1:12).

R. C. Sproul, salah satu dari sekian banyak teolog masyhur pada zaman ini, yang telah menulis banyak buku terkait apologetika, dengan jelas menyatakan bahwa tujuan utama dari kegiatan berapologetika adalah untuk "providing an intellectual defense of the truth claims of the faith" (sproul, 2009). Kata kuncinya ialah terletak pada kata“intellectual defense", atau pembelaan intelektual. Pembelaan intelektual yang sering kali berwujud argumen-argumen yang didasarkan pada berbagai klaim kekristenan untuk mematahkan klaim para penyerang. Dalam berapologetika, para Apologis Kristen harus memberikan jawaban, penjelasan, yang logis dan tepat. Bahkan dalam metode Evidensial, seorang Apologis harus menunjukkan bukti-bukti yang sahih atas doktrinnya (Hutahean, 2019). Dibutuhkan wawasan Alkitab yang kokoh dan juga pemahaman doktrin Kristen yang utuh untuk menjadi seorang Apologis Kristen. Intelektualitas menjadi bagian yang penting.

Dalam berapologetika, John Frame membaginya dalam tiga aspek yang saling berkaitan antara satu dengan yang lainnya:

1. Pembuktian: Memaparkan sebuah dasar rasional mengenai iman Kristen yang sejati dalam menghadapi keraguan dalam diri orang percaya dan hinaan dari orang-orang yang tidak percaya.

2. Pembelaan: Memberikan jawaban terhadap keberatan-keberatan logika mereka yang tida percaya.

3. Penyerangan: Melakukuan penyerangan terhadap kebodohan dari keraguan atau ketidakpercayaan terhadap iman Kristen. Tuhan tentu tida hanya memanggil umat-Nya untuk menjawab seluruh keberatan-keberatan yang ada, melainkan juga peru bersikap offensive terhadap kebodohan akibat keberdosaan manusia (Frame, 2000).

Tentu seluruh aspek ini membutuhkan tanggungjawab yang serius dari seorang apologis Kristen untuk belajar Alkitab dan doktrin Kristen dengan tekun dan bergantung kepada 
pencerahan oleh Roh Kudus. Apologetika adalah sebuah studi untuk mempelajari dan menyelidiki bagaimana menyusun dan melaksanakan suatu pertanggungjawaban yang efektif bagi serangan terhadap iman Kristen (Tanudjaja, 2005).

\section{Apologetika dan Spiritualitas Kristiani}

Spiritualitas dapat didefinisikan sebagai "kualitas atau fakta kerohanian, sesuatu yang tidak bersifat jasmani" atau "ciri rohani yang ditunjukkan melalui pemikiran, cara hidup, dll; kecenderungan atau nada rohani"(Got question, 2020). Roh Kudus yang menjadi meterai orang percaya yang sudah lahir baru. Roh Kudus berdiam di dalam hidup orang percaya (Efesus 1:13; 4:30). Tuhan Yesus berjanji bahwa Roh Kudus akan memimpin orang-orang yang beriman kepada-Nya untuk dapat masuk ke dalam "seluruh kebenaran" (Yohanes 3:16). Roh Kudus akan menuntun dan mengajar setiap orang percaya agar memiliki pengetahuan yang benar dan dapat mengaplikasikan dalam setiap aspek kehidupan. Dapat dipahami bahwa spiritualitas Kristen adalah suatu perjalanan rohani dalam kehidupan orang-orang yang sudah lahir baru. Rasul Paulus meminta agar setiap orang percaya "dipenuhi" oleh Roh Kudus. "Dan janganlah kamu mabuk oleh anggur, karena anggur menimbulkan hawa nafsu, tetapi hendaklah kamu penuh dengan Roh" (Efesus 5:18). Dipenuhi oleh Roh Kudus berarti memberikan keleluasaan bagi Roh Kudus untuk berkuasa penuh dalam diri seseorang. (Sabdono, 2017) Ketika seseorang sedang dalam keadaan mabuk karena anggur, maka secara otomatis akan nampak gejala-gejala tertentu pada orang tersebut, seperti cara bicara yang tidak jelas, sempoyongan, dan tidak dapat mengambil keputusan dengan baik. Bila orang yang sedang mabuk anggur dapat dideteksi melalui gejala-gejala tersebut, maka begitupun dengan orang-orang yang dikuasai oleh Roh Kudus, pasti ciri-cirinya terlihat jelas. Dalam Alkitab ciri-ciri orang yang penuh dengan Roh Kudus dapat dilihat dalam Galatia 5:22-23, yaitu adanya "buah Roh.” Hal ini merupakan suatu karakteristik Kristiani, melalui pekerjaan Roh Kudus yang secara efektif mengendalikan hidup orang percaya.

Setiap orang percaya yang telah mengalami lahir baru akan nampak buah dari kehidupannya. Perkataannya memiliki nilai Agung yang bersumber dari Sang Kebenaran itu sendiri. Oleh karena itu, spiritualitas Kristen adalah sebuah pilihan yang harus diambil seseorang untuk semakin mengenal, mengalami dan bertumbuh di dalam 
Kristus dalam kehidupan kesehariannya. setiap orang percaya harus menjaga komunikasinya dengan Roh Kudus melalui pengakuan dosa yang dilakukan dalam perjalanan hidup, sehingga teruse menuju kepada kesempurnaan (1 Yohanes 1:9). Spiritualitas Kristiani itu merupakan kesadaran seseorang untuk bersekutu dengan Roh Kristus, yang tidak bisa terputus oleh kedagingan dan dosa. Spiritualitas Kristen hanya bisa dimiliki oleh orang-orang yang sudah lahir baru, yang berkomitmen penuh untuk bertumbuh dan berkembang dalam iman kepada Yesus. Orang percaya harus menjaga dirinya agar tida mendukakan Roh Kudus (Efesus 4:30; 1 Yohanes 1:5-8), sebab hal itu akan menjadi penghalang dirinya dengan Allah. Sebaliknya, bila seseorang tunduk kepada pimpinan Roh Kudus, maka hubungan dirinya dengan Allah akan semakin kuat dan memberikan semangat hidup yang meyala-nyala (1 Tesalonika 5:19).

Dalam surat 1 Petrus 3:15-16 tertulis:

"Tetapi kuduskanlah Kristus di dalam hatimu sebagai Tuhan! Dan siap sedialah pada segala waktu untuk memberi pertanggungan jawab (apologia) kepada tiaptiap orang yang meminta pertanggungan jawab dari kamu tentang pengharapan yang ada padamu, tetapi haruslah dengan lemah lembut dan hormat, dan dengan hati nurani yang murni, supaya mereka, yang memfitnah kamu karena hidupmu yang saleh dalam Kristus, menjadi malu karena fitnahan mereka itu."

Menurut John Frame, sebelum masuk medan pertempuran dalam dunia apologetika, para apologis hendaknya mengoreksi ke dalam kehidupan relasional pribadinya dengan Allah. Karena dalam dasar Alkitab di atas, kalimat pertama adalah “Tetapi kuduskanlah Kristus di dalam hatimu sebagai Tuhan!” Sehingga dalam diri seorang apologis dituntut untuk percaya dan berkomitmen penuh pada ketuhanan Kristus karena ini akan mempengaruhi presaposisi yang akan digunakan sebagai pijakan selanjutnya (Frame, 2000). Artinya seseorang apologis Kristen adalah orang yang sudah lahir baru dan memiliki keintiman dengan Tuhan, sehingga bukan hanya kuat dalam berkata-kata, melainkan hidupnya atau perbuatannya menjadi pernyataan yang kuat kepada para penyerang iman Kristen bahwa Injil mengubahkan kehidupannya. Fokus utama dari apologetika ialah agar Tuhan dipermuliakan, oleh karena itu apologis Kristen haruslah orang yang hidupnya saleh. 


\section{Rasul Paulus Sebagai Teladan Intelektualitas dan Spiritualitas}

Rasul Paulus adalah keturunan Yahudi diaspora yang lahir di kota Tarsus, provinsi Kilikia (Kisah Para Rasul 21:39). Dia dilahirkan dalam keluarga Yahudi Dia dilahirkan di dalam keluarga Yahudi yang cukup berada, yang memiliki usaha membuat dan berjualan tenda. Paulus sendiri mengakui bahwa ia memperoleh kewarganegaraan Roma sejak lahir (Kisah Para Rasul 22:28), nampaknya keluarganya memiliki reputasi yang baik sehingga mendapat kewarnegaraan Roma. Paulus hidup di keluarga yang sangat ketat menjalankan aturan agama Yahudi, Hal ini dapat dibaca dalam Filipi 3:4-6: “disunat pada hari kedelapan, dari bangsa Israel, dari suku Benyamin, orang Ibrani asli, tentang pendirian terhadap hukum Taurat aku orang Farisi, tentang kegiatan aku penganiaya jemaat, tentang kebenaran dalam mentaati hukum Taurat aku tidak bercacat." (Novalina, 2020a) Rasul Paulus lahir di Tarsus, namun besar di Yerusalem. Ia didik secara ketat dalam pengawasan Gamaliel, pemimpin sekolah Rabinik yang didirikan oleh Hilel. Alkitab mencatat bahwa track record hidup Paulus adalah seorang yang getol dalam memburu dan menghabisi pengikut Kristus (Kisah Para Rasul 9:2; Galatia 1:13). Namun, setelah dirinya mengalami perjumpaan supranatural dengan Kristus, Paulus berbalik penuh dengan menjadi pemberita Injil yang militan (1 Korintus 2:7; 4:1; Roma 16:25). Kisah pertobatannya dituturkan oleh Lukas sebanyak tiga kali dalam Kisah Para Rasul (9:1-20; 22:1-21; 26:2-23) untuk menyatakan perombakan total seorang yang "melawan” Injil menjadi "pembela" Injil.

Paulus melayani dalam berbagai segmentasi, baik dari bangsanya sendiri, maupun juga kepada bangsa lainnya (Kisah Para Rasul 9:20; 13:5). Paulus memberitakan Injil kepada orang terpelajar dan tidak terpelajar (Roma 1:14), kepada individu maupun komunitas (Kisah Para Rasul 16:14-15, 30-32, 17:22-34), kepada para narapidana di penjara sampai kepada penguni istana (Filipi 1:13-13). Bahkan Raja Herodes Agripa II juga menjadi sasaran pemberitaannya (Kisah Para Rasul 26).

Lebih dari setengah kitab Kisah Para Rasul (Kisah Para Rasul 13-28) berisi catatan perjalanan misi penginjilan Rasul Paulus. Pada bagian akhir Alkitab Terjemahan Baru produksi LAI (Lembaga Alkitab Indonesia) dilampirkan peta perjalanan misi Paulus. Disitu kita menemukan seseorang yang menjejaki tanah Siria hingga Asia Kecil, lalu masuk ke Benua Eropa. Semua ini tidak lain untuk Injil yang sudah mengubahkan hidupnya terlebih dahulu (1 Korintus 9:23). Di dalam diri Paulus, ada kesadaran bahwa 
memberitakan Injil merupakan suatu panggilan yang penuh tanggungjawab (1 Korintus 9:17), bahkan ia secara pribadi terus menerus merasa bahwa memberitakan Injil adalah hutang yang harus dibayar dengan melakukan penginjilan secara berkesinambungan (Roma 1:14). Di dalam surat pertama Paulus kepada jemaat di Korintus tertulis: "Karena jika aku memberitakan Injil, aku tidak mempunyai alasan untuk memegahkan diri. Sebab itu adalah keharusan bagiku. Celakalah aku, jika aku tidak memberitakan Injil.

Paulus adalah seorang teolog yang handal. Beker menuangkan hasil studinya dalam rangka menemukan "pusat teologi” rasul Paulus dalam sebuah buku berjudul Paul the Apostle: The Triumph of God in Life and Thought (Edinburgh: T\&T Clark, 1980). Dalam buku ini, Beker memberikan argumentasinya bahwa teologi rasul Paulus merupakan hasil dari sebuah interaksi kritis antara "the coherent center of the Gospel" dengan the "contingent particularity of the problems" yang senantiasa rasul Paulus jumpai dalam tugas pelayanannya. Menurut Beker, keberhasilan rasul Paulus dalam melaksanakan tugas dan tanggung jawab ini ditentukan oleh kemampuan hermeneutisnya yang tidak hanya "distils a specific core out of the variety of gospel tradition in the early Church but also incarnates that core into the particularity of historical occasions and contexts". Melalui proses hermeneutis inilah rasul Paulus berhasil menarik keluar aspek universal Injil, untuk selanjutnya diterapkan secara kreatif dalam situasi-situasi khusus, sesuai dengan tuntutan pelayanannya. Menurut Beker, cara inilah yang mengakibatkan rasul Paulus sanggup mengkomunikasikan injilnya secara baru dan segar dalam setiap situasi pelayanan yang ia hadapi. Dari sini, maka Beker membuat sebuah kesimpulan tentang diri rasul Paulus dengan berkata:

Paul is neither a rationalistic dogmatist ...nor is he an opportunistic. Compromiser or a thoughtless charismatc.. Rather, he is able to make the gospel a word on target for particular needs of his churches without either compromising its basic content or reducing it to a petrified Conceptuality (J. Christian Beker, 1980).

Dengan kemampuan interpretatif seperti itu maka rasul Paulus sanggup menggabungkan aspek-aspek Injil yang bersifat "partikular dan universal", "beragam dan tunggal". Menurut Beker, isi dasar dari injil rasul Paulus yang juga ia sebut dengan "the coherent 
center" tidak lain adalah "kemenangan Allah" ("the triumph of God"). Kesimpulan ini ia dasarkan pada studi intensifnya atas tiga surat rasul Paulus yakni surat Roma, Galatia, dan 1 Korintus, khususnya fasal 15 yang dianggap Beker sebagai prinsip argumentatif yang menyatukan keseluruhan surat 1 Korintus (Tridarmanto, 2008).

Dibalik kompleksitas berteologi Paulus yang tidak habis-habisnya menjadi kajian teologi baik Biblika, Dogmatika, maupun Historika dapat disimpulkan bahwa Paulus bukan hanya mahir doing theology melainkan juga memiliki kehidupan rohani yang teruji yang juga menjadi kekuatan untuk memberitakan kabar keselamatan yang efektif (Kawangmani, 2019). Dalam Surat 2 Korintus 12:7-9, Rasul Paulus menulis,

"Dan supaya aku jangan meninggikan diri karena penyataan-penyataan yang luar biasa itu, maka aku diberi suatu duri dalam dagingku, yaitu seorang utusan Iblis untuk menggocoh aku, supaya aku jangan meninggikan diri. Tentang hal itu au sudah tiga kali berseru kepada Tuhan, supaya utusan Iblis itu mundur dari padaku. Tetapi jawab Tuhan kepadaku: "Cukuplah kasih karunia-Ku bagimu, sebab justru dalam kelemahanlah kuasa-Ku menjadi sempurna." Sebab itu terlebih suka aku bermegah atas kelemahanku, supaya kuasa Kristus turun menaungi aku.

Banyak tafsiran mengenai makna sesungguhnya dari "duri” dalam daging yang dialami Paulus, apakah hal itu merupakan suatu penyakit, kelemahan fisik atau cacat, atau bahkan suatu keadaan yang sangat sulit yang Paulus jumpai selama perjalanan misinya. Menurut William Barclay dalam bukunya Duta Bagi Kristus: Latar Belakang Peta Perjalanan Paulus, mengemukakan beberapa tafsiran mengenai arti "duri" yang dimaksud(Barclay, 1998): Pertama, merupakan suatu penyakit, dalam konteks sebelumnya Paulus berkata dalam Galatia 4:14,15; Paulus mengatakan kepada jemaat di Galatia bahwa ia memiliki suatu penyakit, dan ia merasa bahagia karena meskipun demikian jemaat Galatia tidak menganggap itu sebagai sesuatu yang hina dan yang menjijikkan. Perlu diketahui secara historikal, orang-orang pada zaman itu berkeyakinan bahwa penyakit ditimbulkan karena adanya roh jahat yang hinggap pada diri seorang yang sakit tersebut, sebab itu ada yang menduga bahwa Paulus memiliki penyakit ayan. Namun hebatnya jemaat Galatia tidak memandang hina dan jijik Paulus. Jijik dalam bahasa Yunani secara harafiah artinya meludahi, jadi jemaat Galatia tidak meludahi Paulus oleh karena penyakitnya, bahkan menerima dia seperti menyambut Kristus. Dan Paulus melanjutkan di Galatia 4:15 dengan mengatakan bahwa 
“jika mungkin kamu mencungkil matamu dan memberikannya kepadaku”. Dari perkataan Paulus ini mengindikasikan bahwa ada sesuatu yang salah dengan matanya. Hal ini juga mungkin saja benar terjadi, ditambah kenyataan bahwa tidak semua surat Paulus ditulisnya sendiri, biasanya ada surat yang ia diktekan dan pada akhirnya dia menulis beberapa kalimat yang isinya salam pribadi dan ia menyertakan tanda tangannya dalam surat tersebut sebagai tanda bahwa benar surat tersebut ia yang menulisnya. Pernyataan ini didukung dengan perkataan Paulus dalam Galatia 6:11 "Lihatlah betapa besarnya huruf-huruf yang kutulis kepadamu dengan tanganku sendiri”. Seakan-akan Paulus sedang menundukkan kepalanya dekat-dekat pada sehelai kertas demi menuliskan suratnya dan ia menyadari bahwa tulisannya sendiri terlalu besar sebab penglihatannya sudah kabur.

Rowan William dalam bukunya Jumpa Allah Dalam Paulus, berpendapat bahwa ada kemungkinan ia menderita salah satu dari sekian banyak penyakit selama perjalanannya, yang menjelaskan kembali bahwa dalam hal penampilan ia tidak menarik, dengan mata bengkak yang bahkan mungkin kelopak matanya bernanah (William, 2014). Dalam kelemahan fisiknya tersebut, Paulus tidak menjadi lemah iman.. Di dalam Alkitab Perjanjian Baru didominasi oleh tulisan-tulisan Paulus kepada jemaat Tuhan yang dikasihinya. Paulus menginjil hingga ke Asia. Buah yang manis dari seorang yang lemah fisik. Tentu semua itu adalah pekerjaan Tuhan melalui kehidupan Paulus yang dipenuhi oleh firman dan ketaatannya kepada kehendak Allah. Sebagai ciptaan baru, kehidupan Rasul Paulus memiliki dampak spiritualitas, yaitu terbebas dari cengkeraman kuasa dosa dan pemerintahan Iblis, sehingga dapat hidup sebagai gambar dan rupa Allah yang telah pulihSebagai ciptaan baru, kehidupan Rasul Paulus memiliki dampak spiritualitas, yaitu terbebas dari kuasa dosa dan pemerintahan Iblis serta dapat hidup sebagai gambar dan rupa yang memancarkan Allah (Darmawan Limasaputra, 2018) dan kehidupannya membawa kesejukan yang nyata kepada masyarakat atau lingkungan keberadaannya sebagai buah spiritualitas warga Kerajaan Allah (Novalina, 2020b)

\section{SIMPULAN}

Seorang Apologis Kristen harus memiliki keseimbangan antara pengetahuan dan perbuatan, antara intelektualitas dan spiritualitas. Sesungguhnya kegiatan 
berapologetika dapat menjadi sarana untuk menumbuhkan spiritualitas kristen dalam diri seseorang, karena melaluinya dia akan belajar banyak tentang Alkitab, dan tentunya firman Tuhan akan menjadi pemuas dahaga jiwa seseorang. Seorang apologis harus memiliki posisi yang jelas, bahwa pembelajaran tersebut bukan hanya untuk orang lain, melainkan juga untuk dirinya sendiri, sebagai fondasi dari setiap perkataan dan perbuatannya. Spiritualitas ibarat dua sisi mata uang yang saling melengkapi dan berdampingan dalam kehidupan seorang Apologis Kristen.

\section{DAFTAR PUSTAKA}

Barclay, W. (1998). DUTA BAGI KRISTUS LATAR BELAKANG PETA PERJALANAN PAULUS. Jakarta: PT BPK Gunung Mulia.

Brown, C. (Ed.). (1975). the new international Dictionary of New Testament Theology (4th editio). Grand Rapids, MI: Zondervan.

Dahle, L. (2013). Truth, Christian Mission and Apologetics: A Response and A Proposal. NORSK TIDSSKRIFT FOR MISJONSVITENSKAP, 1.

Darmawan Limasaputra, A. (2018). Memandang Penderitaan Melalui Perspektif The Already and The Not Yet dari Rasul Paulus. Veritas : Jurnal Teologi Dan Pelayanan, 17, 43-60. https://doi.org/https://doi.org/10.36421/veritas.v17i1.305

Djadi, J. (2003). Apologetika Tentang Kristologi. Jurnal Jaffray, 1 . https://doi.org/http://dx.doi.org/10.25278/jj71.v1i1.167

Frame, J. M. (2000). Apologetika bagi Kemuliaan Allah: Sebuah Pengantar. Momentum.

Got question. (2020.). Apa perbedaan antara agama dan spiritualitas?

Hutahean, T. (2019). SIGNIFIKANSI APOLOGETIKA DALAM PENGINJILAN. STULOS, 17, 54-74.

J. Christian Beker. (1980). Paul the Apostle: The Triumph of God in Life and Thought. Edinburgh: T\&T Clark.

Kawangmani, S. (2019). POLA APOLOGETIKA KONTEKSTUAL UNTUK MEMBERITAKAN KABAR BAIK KEPADA SUKU JAWA WONG CILIK. Jurnal Gamaliel : Teologi Praktika, 1(2).

https://doi.org/https://doi.org/10.38052/gamaliel.v1i2.40

Novalina, M. (2020a). Mengenal Paulus dan Teologinya (1st ed.). Bogor: Lindan 
Bestari.

Novalina, M. (2020b). Spiritualitas Orang Kristen Dalam Menghadirkan Kerajaan Allah di Tengah Tantangan Radikalisme. Jurnal Teologi Kontekstual Indonesia, 1(1), 26. https://doi.org/10.46445/jtki.v1i1.293

Pratiwi, A. (2020). KRITIK ATAS PRINSIP OBJEKTIVITAS DALAM KODE ETIK AKUNTAN MENURUT PEMIKIRAN MARTIN LUTHER. Jurnal Ilmiah

Mahasiswa Fakultas Ekonomi Dan Bisnis, 4(2).

Sabdono, E. (2017). Hidup Menurut Roh. Jakarta: Rehobot Literature.

sproul, R. (2009). Defending Your Faith: An Introduction to Apologetics. wheaton: crossway.

Stackhouse, Jr., J. G. (2002). Humble Apologetics: Defending the Faith Today. New York: Oxford University Press.

Taufik. (2020). ANTARA MARTIN LUTHER DAN MUHAMMAD

ABDUH:ReformasiAgamaPerspektif Sosiologi Kebudayaan dan Politik Kegamaan. Al-IttihadJurnal Pemikiran Dan Hukum Islam, 6, 1-26.

Tri Handoko, Y. (n.d.). Apologetika: Apa dan Bagaimana?

Tri Handoko, Y. (2018). Mengapa Kita Tidak Membela Agama Kita? Retrieved

December 23, 2020, from https://rec.or.id/article_856_Mengapa-Kita-Tidak-

Membela-Agama-Kita

Tridarmanto, Y. (2008). MELACAK KEMBALI METODOLOGI RASUL PAULUS DALAM BERTEOLOGI. Gema Teologi, 32.

Tulung, J. M. (2020). PEMIKIRAN TEOLOGIS EDUKATIF YOHANES CALVIN SERTA RELEVANSINYA BAGI PENDIDIKAN BERGEREJA MASA KINI. Tumou Tou, VII, 11-26.

William, R. (2014). Jumpa Allah Dalam Paulus. Jakarta: Waskita Publishing.

Yosia, A. (2018). Merupa Teater Kemuliaan Allah Sebagai Ruang Publik: Suatu Usaha untuk Mengonstruksi Suatu Ruang Publik Lewat Pemikiran John Calvin dan Ninian Smart di dalam konteks Agama-agama Dunia. Indonesian Journal of Theology, 6, 114-137. https://doi.org/https://doi.org/10.46567/ijt.v6i2.9 